\title{
Assessing Productivity of Personal Selling Effort in India: An Econometric Approach
}

\author{
Mehir Kumar Baidya \\ IISWBM, India \\ Bipasha Maity \\ Future Institute of Engineering and Management, India \\ Kamal Ghose \\ Lincoln University, New Zealand
}

\begin{abstract}
There were not many studies dealt with productivity issues of personal selling effort in FMCG sector around the world. A modest attempt has been taken to assess the productivity of this effort by considering two brands (A \& B) of two firms in India. Time-series data on sales and different marketing mix variables (advertising, sales force, promotion, distribution and price) in rupees have been collected for both the brands in question. Regression models (two multiplicative and one linear) are taken into consideration and fitted on data to estimate the adjusted sales response function to personal selling effort. Results suggest that the productivity of personal selling effort is higher for brand $\mathrm{B}$ than brand $\mathrm{A}$ and varies between the two brands. Findings will assist the managers to invest resources in this effort along with other elements in marketing mix more precisely.
\end{abstract}

Keywords: Investment, Time-series data, Regression, Productivity, India

\section{Introduction}

To develop, maintain and sustain a competent team of sales personnel needs a high degree of investment (money, time, energy, etc.) in all the nations in general and developing ones in particular like India (Skiera and Albers, 2008). This investment is huge and claims a lion share of marketing budget in the case of any brand belongs to any product category in any type of industry (Manchanda and Chintagunta, 2004).

The costs of recruiting, training, developing and deploying a professional team are all-time high (Cespedes, 1990; Erevelles et al., 2004). Further, the personal selling element is the most expensive mode of communication among all the efforts in marketing mix on a straight cost-per contact basis in all sectors (Murthy and Mantrala, 2005). In addition, the sales personnel turnover ratio is continue to be high due to their low level of organizational loyalty added substantial costs to maintain a competent sales force team (Jackson et al., 1994; Sager et al., 1988, 1989).

Previous studies suggest that the managers have been investing resources in personal selling effort 
1999). Moreover, personal selling effort usually offers a relatively quick response of sales as compared to other efforts as well as it may not have only a short-term effect. However, the response depends on different selling approaches those have to be adopted in the contexts of dynamics environment, customers and trade-partners requirements (Cardozo and Ship, 1987; Cravens et al., 1990; Plank and Dempsey, 1980; Verbeke et al., 2004). Further, the response is intending to increase in sales sometimes but do not always profitable (Power, 1989; Person and Abeele, 1981). The selling effort is sometimes failed to generate desired response because there might a lack of adequate support from the top management, customers, situational variables as well as the difference between self-reported past performance and self-generated expectation of future performance (DeCarlo et al., 1999, 2007; Ingram et al., 1992; Jaramillo and Mulki, 2008; Krishna et al., 2002; Roberts et al., 1994).

In above few paragraphs some issues of personal selling effort have been discussed in overall context. To be more specific, an exploratory research has been done in the hair-oil product sector in West Bengal, India. Results reveal that the sample managers are investing a huge sum of money in personal selling effort and doing so, on the basis of their experience, intuition, hunch, etc. And have no clear idea about how to assess the productivity in financial terms of this effort. However, without knowing the productivity, there might be a chance of continuation of an ineffective sales team and a risk of misallocation of funds on useless activities.

In the above backdrop, the following one basic, yet managerially important research question has been identified:

What is the impact of personal selling effort on sales? Does this impact vary between one brand and the other? What is the productivity per one rupee investment in this effort of marketing mix?

In this study, a modest attempt has been taken to address the question empirically by taking into consideration of two brands (A \& B) of two firms in the hair-care product sector in West Bengal, India. At the time of this study, there were 11 firms in the defined research area. All the firms have been approached to participate but none of them except two (A \& B) have agreed to share the required unpublished time-series data for the purpose of this research.

\section{Methodology}

All the relevant models followed by types of data along with methods of analysis have been presented below:

\section{Models}

Two double-log regression models (equations 1 and 2) and a linear regression model (equation 3) have been considered and postulated as:

$$
\begin{aligned}
& Y_{t}=A X_{1 t}^{\beta_{1}} X_{2 t}^{\beta_{2}} X_{3 t}^{\beta_{3}} X_{4 t}^{\beta_{4}} P_{t}^{\beta_{p}} u_{t}, \text { For } t=1,2, \ldots, 24 . \\
& Y_{t}=B X_{1 t}^{\lambda_{1}} X_{3 t}^{\lambda_{3}} X_{4 t}^{\lambda_{4}} P_{t}^{\lambda_{p}} v_{t}, \text { For } t=1,2, \ldots, 24 . \\
& Y_{t}(\text { Adjusted })=\alpha+\delta X_{2 t}+w_{t}, \text { For } t=1,2, \ldots, 24 .
\end{aligned}
$$


where, $Y_{t}=$ Sales in rupees in period $\mathrm{t}, X_{1 t}=$ Advertising expenditures in terms of rupees for period $\mathrm{t} ; X_{2 t}=$ Sales force / personal selling expenditures in terms of rupees for period $\mathrm{t} ; X_{3 t}=$ Promotion expenditures in terms of rupees for period t; $X_{4 t}=$ Distribution expenditures in terms of rupees for period $\mathrm{t} ; P_{t}=$ Price of the brand in terms of rupees for period $\mathrm{t} ; \delta=$ Regression coefficient of personal selling effort in equation (3) and it represents productivity, which is defined as change in nominal sales for one rupee change in investment in this effort; $u_{t}=$ Random disturbance term for period $\mathrm{t}$ in equation (1); $v_{t}=$ Random disturbance term for period $\mathrm{t}$ in equation (2) and $w_{t}=$ Random disturbance term for period $\mathrm{t}$ in equation (3).

These forms (equations 1 and 2) have been taken into consideration since many empirical studies support diminishing marginal return to individual marketing efforts (Basu and Batra, 1988; Simon and Arndt, 1980; White et al., 2001). However, a linear form (equation 3) has been shorted to estimate productivity of personal selling effort in this work. Since an S-shaped response curve can be treated as straight line for a limited range of and not so prominent variation (as the case may be) in individual marketing efforts (Freeland and Weinberg, 1980; Mjelde, 1983).

\section{Data and Methods of Analysis}

Quarterly time-series data on sales, price and various marketing efforts (advertising, personal selling, promotion and distribution) in rupees have been gathered for two brands (A \& B) over a period 2003-2008.

The empirical analyses have been carried out in several stages. In the first stage, to identify the recurring pattern in the data, the seasonal indices have been calculated for all the variables for both the cases (Makridakis et al., 1998). For computing the adjustment factors for seasonality, the combined effects of trend and cyclical variation have been measured by the moving average method. Then the adjusted seasonal indices have been calculated by the appropriate averaging of the ratios of the original values to the moving averages and the use of a suitable correction factor. Moreover, a few extreme observations have been deleted by following the appropriate tests for outlier in both the cases.

In the next stage, a double-log regression model has been fitted on purified data by considering sales (in rupees) as dependent variable and advertising, sales force, promotion, distribution and price are as predictors. This defined equation is used to estimate quarter-wise sales for both the brands.

In the third stage, a multiple regression analysis with ordinary least squares (OLS) algorithm has been performed between sales and advertising, promotion, distribution with price. Again, this equation is utilized to estimate quarter-wise sales in both the cases. Then, the calculated values of sales (in stage three) have been subtracted from the calculated values of sales (in stage two) to obtain the adjusted sales for other marketing efforts except personal selling for further analysis.

Finally, a linear regression analysis with ordinary least squares (OLS) algorithm has been performed on the quarterly estimated adjusted sales (mentioned above) and personal selling effort data for both the brands. The estimated parameter has been interpreted as productivity (change in sales per one rupee change in investment) since a linear regression model has been used in this purpose. 
Findings of this work have been presented and discussed in this section.

Results of regression analysis (equation 1) between sales and advertising, sales force, promotion, distribution and price have been presented in Table 1.

Table 1 Coefficients of Sales Equation (1) for A and B

\begin{tabular}{|l|c|c|c|c|}
\hline Predictor & \multicolumn{2}{|l|}{ Elasticity } & \multicolumn{2}{l|}{ Null Hypotheses of Zero Elasticity } \\
& \multicolumn{3}{|l}{} & $\left(\beta_{i}=0\right)$ \\
\cline { 4 - 5 } & & $\mathrm{B}$ & $\mathrm{A}$ & $\mathrm{A}$ \\
\cline { 2 - 5 } & $\mathrm{A}$ & 0.116 & $1.85^{* * *}$ & $1.81^{* * *}$ \\
\hline$A D$ & 0.750 & 1.350 & $7.10^{*}$ & $5.35^{*}$ \\
\hline$S F$ & 1.250 & 0.114 & $5.25^{*}$ & $1.70^{* * * *}$ \\
\hline$P M$ & 0.052 & 0.323 & $1.70^{* * *}$ & $1.71^{* * *}$ \\
\hline$D I S T$ & 0.623 & -1.15 & $-8.46^{*}$ & $-3.88^{*}$ \\
\hline$P$ & -0.90 & &
\end{tabular}

Note: $\mathrm{AD}=$ Advertising, $\mathrm{SF}=$ Sales force, $\mathrm{PM}=$ Promotion, $\mathrm{DIST}=$ Distribution, $\mathrm{P}=$ Price, ${ }^{*} p<0.001$ (onetail), ${ }^{* * *} p<0.05$ (one-tail).

Findings reveal that the sales in rupees have significant positive association with individual marketing efforts such as advertising, sales force, promotion and distribution for both the brands. However, the price has significant negative relationship with sales in both the cases as expected. Validation statistics of this equation appear in Table 2.

Table 2 Validation Statistics for Equation (1)

\begin{tabular}{|l|l|l|l|}
\hline Brand & \multicolumn{1}{|c|}{$\mathrm{R}^{2}$} & \multicolumn{1}{|c|}{ F-value } & DW \\
\hline A & 0.90 & $70.24^{*}$ & 2.05 \\
\hline $\mathrm{B}$ & 0.97 & $158.50^{*}$ & 2.10 \\
\hline
\end{tabular}

Note: ${ }^{*} p<0.001, \mathrm{DW}=$ Durbin-Watson Statistic.

It is found that the $\mathrm{R}^{2}$ values are notably high for both the brands. That is, sales as a double-log function of individual marketing efforts with price provide a good fit to the observed data for both the brand. Further, the results indicate, both the values of DW statistic are insignificant, which would lead to the conclusion that there is no evidence of significant autocorrelation of the error terms in both the cases.

A second regression analysis (equation 2) has been performed between sales and advertising, promotion, distribution with price. Results are shown in Table 3.

Table 3 Coefficients of Sales Equation (2) for A and B

\begin{tabular}{|l|l|l|l|c|}
\hline Predictor & \multicolumn{2}{|l|}{ Elasticity } & \multicolumn{2}{l|}{$\begin{array}{l}\text { Null Hypotheses of Zero Elasticity } \\
\left(\lambda_{i}=0\right)\end{array}$} \\
\cline { 3 - 5 } & \multicolumn{2}{|l|}{} & $\mathrm{A}$ & $\mathrm{B}$ \\
\cline { 2 - 5 } & $\mathrm{A}$ & $\mathrm{B}$ & $\mathrm{t}$ & $\mathrm{t}$ \\
\hline
\end{tabular}




\begin{tabular}{|l|l|l|l|l|}
\hline$A D$ & 0.650 & 0.216 & $1.87^{* * *}$ & $1.70^{* * *}$ \\
\hline$P M$ & 0.051 & 0.426 & $4.56^{*}$ & $1.70^{* * *}$ \\
\hline$D I S T$ & 0.440 & 0.312 & $1.77^{* * *}$ & $1.85^{* * *}$ \\
\hline$P$ & -01.10 & -1.42 & $-7.79^{*}$ & $-4.50^{*}$ \\
\hline
\end{tabular}

Note: $\mathrm{AD}=$ Advertising, $\mathrm{SF}=$ Sales force, $\mathrm{PM}=$ Promotion, DIST $=$ Distribution, $\mathrm{P}=$ Price, ${ }^{*} p<0.001$ (onetail), ${ }^{* * *} p<0.05$ (one-tail).

Findings suggest that the sales (in rupees) have significant positive relationship with advertising, promotion and distribution except for price in both the cases. Results are shown in Table 4.

Table 4 Validation Statistics for Equation (2)

\begin{tabular}{|l|l|l|l|}
\hline Brand & \multicolumn{1}{|c|}{$\mathrm{R}^{2}$} & \multicolumn{1}{c|}{ F-value } & \multicolumn{1}{c|}{$\mathrm{DW}$} \\
\hline $\mathrm{A}$ & 0.85 & $60.24^{*}$ & 2.11 \\
\hline $\mathrm{B}$ & 0.89 & $100.50^{*}$ & 1.98 \\
\hline
\end{tabular}

Note: ${ }^{*} p<0.001, \mathrm{DW}=$ Durbin-Watson Statistic.

There is no qualitative difference between validation statistics of equation (2) in Table 4 and validation statistics of equation (2) in Table II hence claim similar interpretation as presented above.

The third regression analysis (equation 3) has been carried out between adjusted sales and personal selling effort. Results are presented in Table 5.

Table 5 Coefficients of Sales Equation (3) for A and B

\begin{tabular}{|l|c|c|c|c|}
\hline Predictor & \multicolumn{2}{|l|}{ Coefficient } & \multicolumn{2}{l|}{$\begin{array}{l}\text { Null Hypotheses of Zero Coefficient } \\
\end{array}$} \\
\cline { 2 - 5 } & \multicolumn{2}{|l|}{$(\delta=0)$} \\
\cline { 2 - 5 } & $\mathrm{A}$ & $\mathrm{B}$ & $\mathrm{A}$ & $\mathrm{B}$ \\
\hline Constant & 0.91 & -1.82 & $21.60^{*}$ & $-15.15^{*}$ \\
\hline PSE & 18.50 & 102.91 & $10.45^{*}$ & $23.75^{*}$ \\
\hline
\end{tabular}

Note: PSE $=$ Personal Selling Effort, ${ }^{*} p<0.001$ (one-tail).

Results reveal that the personal selling effort has a positive effect on sales for both the brands. That is, per rupee increase in expenditure on this effort would lead to increase sales for both the brands. Here, it has been observed that sales would increase by 18.50 and 102.91 rupees for an additional rupee investment in this effort for A and B respectively. To test whether the personal selling effort has a significant positive effect on adjusted sales, the following hypothesis has been formulated for both the brands with respect to equation 3 .

$H$ : Expenditure on personal selling effort would have a positive effect on adjusted sales. That is, in mathematical form, $H_{0}: \delta=0$ against $H_{a}: \delta>0$

Results in Table V have confirmed the above-mentioned hypothesis for both the brands. That is, the personal selling effort has significant positive effect on adjusted sales in both the cases. However, 
the effect is more rigorous (on the basis of $t$ values) in the case of $B$ than in the case of $A$.

Table 6 Validation Statistics for Equation (3)

\begin{tabular}{|l|l|l|l|}
\hline Brand & \multicolumn{1}{|c|}{$\mathrm{R}^{2}$} & \multicolumn{1}{c|}{ F-value } & DW \\
\hline $\mathrm{A}$ & 0.91 & $130.80^{*}$ & 1.89 \\
\hline $\mathrm{B}$ & 0.95 & $140.25^{*}$ & 1.93 \\
\hline
\end{tabular}

Note: ${ }^{*} p<0.001, \mathrm{DW}=$ Durbin-Watson Statistic.

Results indicate that the $\mathrm{R}^{2}$ values are notably high for both the brands. That is, adjusted sales as function of personal selling effort provide a good fit to the observed data for both the brands. Further, both the values of DW statistic claim similar qualitative interpretation as mentioned earlier in both the cases.

An alternative way to understand the differential effect of personal selling effort in generating sales is examining the productivity. Productivity has been defined as increase in revenue per one rupee investment in personal selling effort in this study. Further, productivity is basically an alternative way to represent the estimated coefficient of personal selling effort instead of elasticity since a linear form of relationship has been used. Results show that the productivity of personal selling effort is much higher in the case of B than in the case of A. That is, the manager of this brand (B) utilized this effort more efficiently than the rival brand (A).

\section{Conclusion}

This paper examines the effects of different marketing mix variables on sales in rupees with special interest in personal selling effort for two brands in India. Hence, sales have been given adjustment for other marketing efforts. Results of this study reveal that the personal selling effort has significant positive effect on adjusted sales and this effect varies from one brand to another. Coming to the productivity of personal selling effort, it has been observed that the sales personnel of brand $\mathrm{B}$ are more efficient than brand A.

This study ignores completely the interaction between personal selling effort and other efforts in marketing mix due to small number of observations. Nor does it include those factors, which influences the productivity of sales personnel since data were not available with both the firms.

Researchers will expand the current study from a two-brand analysis in a single sector to a multibrand one covering a number of sectors to identify the differential effect of personal selling effort on sales from one sector to another.

\section{Implications for Business Marketing Practice}

Findings of this research might have at least two important business implications. On one hand, the managers of both the brands could allocate a fixed budget to different marketing efforts in general and personal selling effort in particular by using the estimated sales response functions more precisely. On the other hand, the managers should increase in investment in personal selling effort to boast up in sales since productivity of this element is high. That is, they should increase the number of sales personnel for better coverage in the existing markets. 


\section{References}

Basu, A.K. and Batra, R. (1988), “ADSPLIT: A multi-brand advertising budget allocation model”, Journal of Advertising, vol. 17, no. 2, pp. 44-51.

Cardozo, R. and Shipp, S. (1987), "New selling methods are changing industrial sales management", Business Horizons, vol. 30, no. 5, pp. 23-38.

Cespedes, F.V. (1990), “A preface to payment: Designing a sales compensation plan”, Sloan Management Review, vol. 32, no. 1, pp. 59-69.

Cravens, D.W., Moncrief, W.C., Lamb, C.W. Jr. and Dielman, T. (1990), "Sequential modeling approach for redeploying selling effort in field sales forces", Journal of Business Research, vol. 20, no. 3, pp. 217-233.

DeCarlo, T.E., Agarwal, S. and Vyas, S.B. (2007), "Performance expectations of salespeople: The role of past performance and causal attributions in independent and interdependent cultures", Journal of Personal Selling \& Sales Management, vol. 27, no. 2, pp. 133-148.

DeCarlo, T.E., Rody, R.C. and Decarlo, J.E. (1999), “A cross-national example of supervisory management practices in the sales force", Journal of Personal Selling \& Sales Management, vol. 19, no. 1, pp. 1-14.

Erevelles, S., Dutta, I. and Galantine, C. (2004), "Sales force compensation plans incorporating multidimensional sales effort and salesperson efficiency", Journal of Personal Selling \& Sales Management, vol. 24, no. 2, pp. 101-112.

Freeland, J.R. and Weinberg, C.B. (1980), "S-shaped response functions: Implications for decision models", Journal of the Operation Research Society, vol. 31, no. 11, pp. 1001-1008.

Ingram, T.N., Schwepker, C.H. and Hutson, D. (1992), "Why salespeople fail”, Industrial Marketing Management, vol. 21, no. 3, pp. 225-230.

Jackson, D.W. Jr., Tax, S.S. and Barnes, J.W. (1994), "Examining the sales force culture: Managerial applications and research propositions", Journal of Personal Selling \& Sales Management, vol. 14, no. 4, pp. $1-14$.

Jaramillo, F. and Mulki, J.P. (2008), "Sales effort: The intertwined roles of the leader, customers, and the salesperson”, Journal of Personal Selling \& Sales Management, vol. 28, no.1, pp. 37-52.

Krishna, B.C., Netemeyer, R.G. and Boles, J.S. (2002), "Self-efficiency, competitiveness, and efforts as antecedents of salesperson performance", Journal of Personal Selling \& Sales Management, vol. 22, no. 4, pp. 285-296.

Makridakis, S., Wheelwright, S. and Hyndman, R.J. (1998), Forecasting: Methods and Applications, John Wiley \& Sons, England.

Mjelde, K.M., (1983), "Fractional resource allocation with S-shaped response functions", Journal of the Operational Research Society, vol. 34, no. 7, pp. 627-633.

Murthy, P. and Mantrala, M.K. (2005), "Allocating a promotion budget between advertising and sales context prices: An integrated marketing communication perspective", Marketing Letters, vol. 16, no. 1, pp. 19-36. 
Person, L.J. and Abeele, P.V. (1981), “Analysis of sales calls effectiveness”, Journal of Marketing Research, vol. 18, no. 1, pp. 107-113.

Plank, R.E. and Dempsey, W.A. (1980). “A framework for personal selling to organization”, Industrial Marketing Management, vol. 9, no. 2, pp. 143-149.

Powers, T.L. (1989), "Should you increase sales promotion or add more salespeople?" Industrial Marketing Management, vol. 18, no. 4, pp. 259-263.

Roberts, J.A., Lapidus, R.S. and Chonko, L.B. (1994), “An exploratory examination of situational variables, effort and salesperson performance", Journal of Marketing Theory and Practice, vol. 2, no. 3, pp. 70-94.

Sager, J.K., Futrell, C.M. and Varadarajan, R. (1989), "Exploring salesperson turnover: A causal model”, Journal of Business Research, vol. 8, no. 1, pp. 21-35.

Sager, J.K., Varadarajan, P.R. and Futrell, C.M. (1988), "Understanding salesperson turnover: A partial evaluation of Moblay's turnover process model”, Journal of Personal Selling \& Sales Management, vol. 8 , no. 1, pp. 21-35.

Simon, J.L. and Arndt, J. (1980), "The shape of the advertising response function", Journal of Advertising Research, vol. 20, no. 4, pp. 11-20.

Skiera, B. and Albers, S. (2008), "Prioritizing sales force decision areas for productivity improvements using a core sales response function", Journal of Personal Selling \& Sales Management, vol. 28, no. 2, pp. 145154.

Thevaranjan, A. and Joseph, K. (1999), "Incentive and job resign: The case of the personal selling function", Managerial and Decision Economics, vol. 20, no. 4, pp. 205-216.

Verbeke, W., Belschak, F. and Bagozzi, R.P., (2004), "The adaptive consequences of pride in personal selling”, Journal of the Academy of Marketing Science, vol. 32, No. 4, pp. 386-402.

White, J.B., Miles, M.P. and Smith, M.F. (2001), "The interrelationship of marketing productivity and financial performance for global SMEs”, Irish Marketing Review, vol. 14, no. 1, pp. 55-60.

\section{Acknowledgement}

The authors gratefully acknowledge the constant support of Dey's Medical Ltd. and Emami Ltd. as well as providing unpublished internal data for the purpose of this research. 